\title{
Mitral valve replacement with the pulmonary autograft: The Ross II procedure
}

\author{
A. Sampath Kumar, MCh, Saket Aggarwal, MS, and Shiv Kumar Choudhary, MCh, New Delhi, India
}

From the Cardiothoracic Centre, All India Institute of Medical Sciences, Ansari Nagar, New Delhi, India.

Received for publication Nov 30, 2000 accepted for publication Jan 2, 2001.

Address for reprints: A. Sampath Kumar, Professor, Department of Cardiothoracic \& Vascular Surgery, Ansari Nagar, New Delhi-110 029, India (E-mail: askumar@medinst.ernet.in asampath_kumar@hotmail.com).

J Thorac Cardiovasc Surg 2001;122:378-9

Copyright (C) 2001 by The American Association for Thoracic Surgery

$0022-5223 / 2001 \$ 35.00+0 \quad \mathbf{1 2 / 5 4} / \mathbf{1 1 4 0 9 5}$

doi:10.1067/mtc.2001.114095
$\mathrm{T}$

he search for an ideal valve substitute continues. Although Ross ${ }^{1}$ described the use of a pulmonary autograft for mitral valve replacement in 1967, interest in this operation only now is being renewed because of the many advantages. ${ }^{2,3}$ We report one such operation with a technique that was developed in our center.

\section{Patient and Methods}

A 35-year-old man had had progressive shortness of breath and palpitations for 6 years. Clinical examination showed classic features of severe mitral stenosis with severe pulmonary arterial hypertension. The transthoracic echocardiogram showed severe calcific mitral stenosis with a mitral valve area of $0.6 \mathrm{~cm}^{2}$. There was no other valvular involvement. He was admitted for mitral valve replacement.

Transesophageal echocardiography was performed soon after intubation. The pulmonary valve anulus measured $29 \mathrm{~mm}$ in diameter with a normal structure. The heart was approached through a median sternotomy and vertical pericardiotomy. The pulmonary artery was carefully dissected free of the aorta and looped. A marker suture was placed on the pulmonary artery just at the distal end of the sinuses. Moderately hypothermic $\left(28^{\circ} \mathrm{C}\right)$ cardiopulmonary bypass was established with aortic and bicaval cannulation. Cold blood cardioplegia and topical ice slush were used for myocardial protection. The left atrium was opened and retracted with a Cooley retractor. The mitral valve was severely stenosed and calcified. No thrombus was found in the atrium or in the appendage. The valve was excised, preserving the subvalvular apparatus.

The pulmonary artery was incised just distal to the marker stitch and transected, with care taken to leave a 2-mm rim of pulmonary artery beyond the commissural pillars. The pulmonary valve was inspected and found to be tricuspid and competent. The right ventricular outflow tract was incised 3 to $4 \mathrm{~mm}$ proximal to the pulmonary anulus. With careful dissection, the autograft was explanted and hemostasis was secured. The pulmonary anulus measured $29 \mathrm{~mm}$. Three sutures were then passed through the mitral anulus at equidistant points. These sutures were then passed through the top of the autograft commissures with the autograft in an upside-down position. The sutures were tied. The autograft was inverted into the left ventricle, and the distal end of the autograft was sutured completely to the mitral anulus in a continuous fashion. An appropriate sized stent was fashioned with thick nonporous Teflon felt (Figure 1). The circumference was measured with a 29-mm valve sizer, and the height of the pillars was the height of the pulmonary valve commissures. Three additional sutures were placed at the point of the commissural sutures, and these were passed through the top of the pillars of the stent. The stent ends were closed with a suture to form a ring support to the pulmonary autograft at its proximal end. Three sutures were passed through the pulmonary autograft at the commissures about $2 \mathrm{~mm}$ below the pillars. These sutures were passed through the ring of the stent at the appropriate points and though the left atrial wall, which was gathered $2 \mathrm{~cm}$ upstream of the mitral anulus. These were tied and run continuously as the proximal suture line for the 


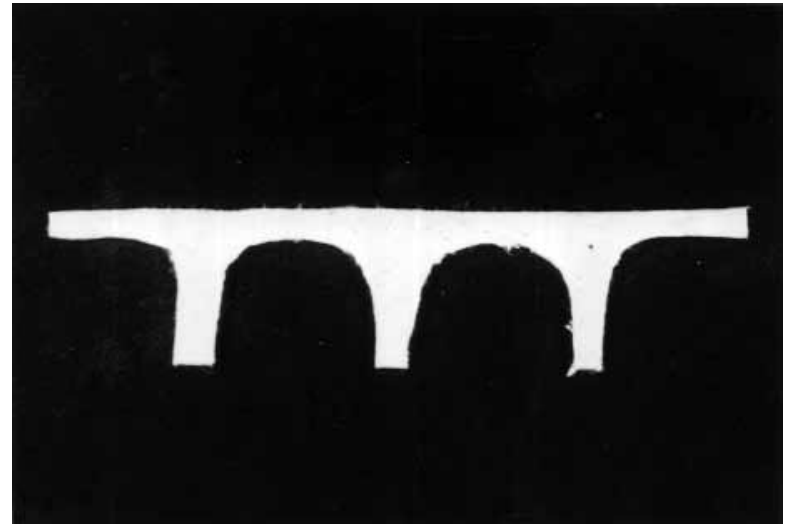

Figure 1. The stent, designed from thick nonporous Teflon felt.

autograft, incorporating the ring stent. The sutures were tightened with a nerve hook and tied. Figure 2 shows the anatomy after completion of autograft insertion. The valve was tested for competence by injection of saline solution into the left ventricle with a bulb syringe and was found to be competent.

The right ventricular outflow tract was reconstructed with a cryopreserved pulmonary homograft obtained from our own tissue valve bank. The heart was deaired, the patient was rewarmed to $37^{\circ} \mathrm{C}$, and bypass was discontinued.

\section{Results}

The cardiopulmonary bypass time was 130 minutes and the aortic clamp time was 100 minutes. Transesophageal echocardiography confirmed good autograft function with no mitral regurgitation and no gradient across the valve (Figure 3 ). The postoperative recovery was smooth, and the patient was discharged on the 10th postoperative day. Transthoracic echocardiography before discharge showed a functioning autograft without any stenosis or regurgitation. The patient is doing well 3 months after the operation.

\section{Discussion}

The renewed interest in the use of the pulmonary autograft for the mitral valve as reported by Kabbani and associates ${ }^{2}$ prompted us to attempt this in our patients because of the many advantages offered by the autograft. Our technique differs from those reported by Ross, ${ }^{1}$ Yacoub and Kittle, ${ }^{4}$ and Kabbani and associates ${ }^{2}$ in that we have not used a top-hat technique. Instead, we fashioned a stent with Teflon felt, which was used to support the autograft and provided certain advantages. The stent is completely buried and does not come in contact with the bloodstream. The stent is somewhat similar in shape and size to the stent used for bioprosthetic valves and is easily fashioned on the table with the measurements taken from the autograft itself. The autograft sinuses are intact and free to billow during valve closure, as was observed during echocardiography after the operation, providing physiologic function to the valve. Unlike the top-hat technique, here the valve is not restrained within a prosthetic graft tube.

We thank Dr Akhil Govil for Figure 2.

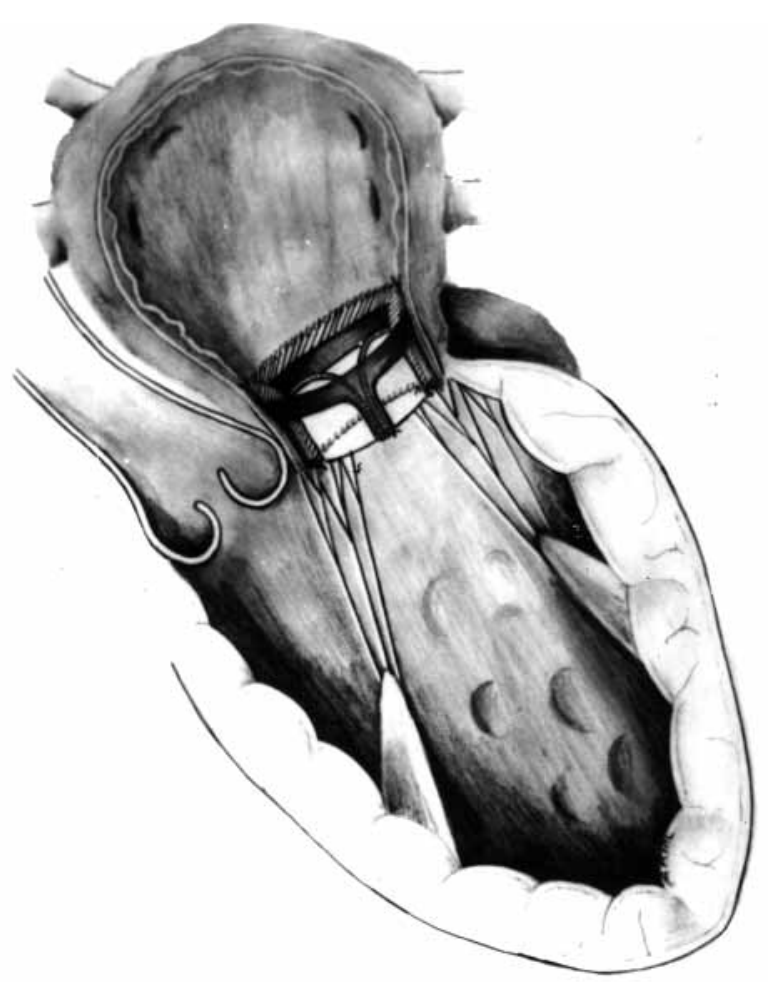

Figure 2. Diagram of the completed autograft implantation.

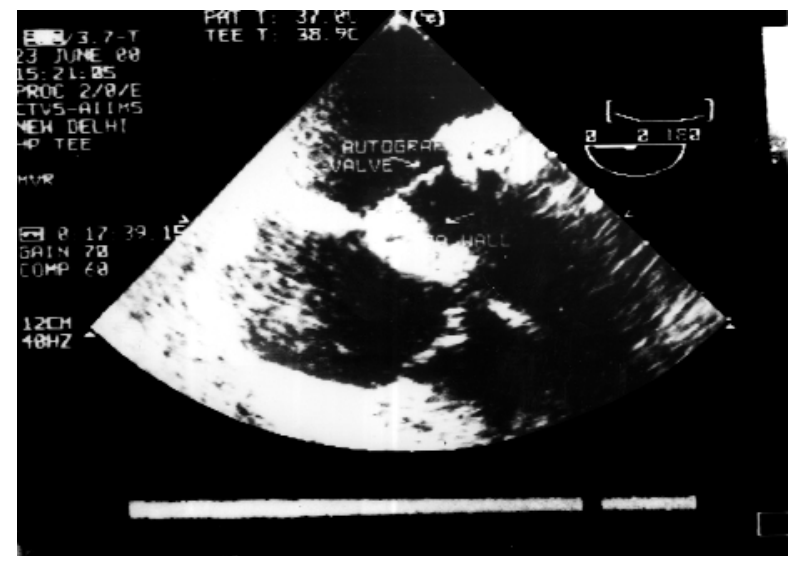

Figure 3. Two-dimensional transesophageal echocardiogram showing the pulmonary autograft in the left atrium.

\section{References}

1. Ross DN. Replacement of aortic and mitral valves with a pulmonary autograft. Lancet. 1967;2:956-8.

2. Kabbani SS, Ross DN, Jami H, Hammoud A, Nabhani F, Hariri R, et al. Mitral valve replacement with a pulmonary autograft: initial experience. J Heart Valve Dis. 1999;8:359-67.

3. Al Hales ZA, Awad MM, Pielers F, Shahid MS, Al Amri MA. Six-year follow-up of a pulmonary autograft in the mitral position: the Ross II procedure. J Thorac Cardiovasc Surg. 1999;117:614-6.

4. Yacoub MH, Kittle CF. A new technique for replacement of the mitral valve by a semilunar valve homograft. $J$ Thorac Cardiovasc Surg. 1969;58:859-69. 